\title{
The Pharmacy Audit: What Is It and Are You Prepared?
}

The mere mention of the word "audit" invokes uneasiness among managers, but with billions of dollars expended annually on pharmaceuticals, eventually your department will be the subject of a pharmacy audit. This article presents an overview of the audit process and guidelines that every professional should know.

\section{Terri Bernacchi}

\section{Anthor}

TERRI BERNACCHI, R.PH., M.B.A, is President, Innovative Health Strategies, Inc., Milwaukee, WI. IHS, Inc., is a health care consulting and medical informatics company specializing in the pharmacy benefit area.

AUTHOR CORRESPONDENCE: Teri Bernacchi, R.Ph., M.B.A., Innovative Health Strategies, Inc., 633 W. Wisconsin Ave., Suite 1009, Milwaukee, WI 53233.

Copyright@ 1999, Academy of Managed Care Pharmacy, Inc. All rights reserved.
$\mathrm{P}$ harmaceutical expenditures in the United States, estimated to be in the billions, increased by $14.2 \%$ in 1997. ${ }^{1}$ This growth, largely attributed to increased pharmaceutical utilization and newly patented pharmaceuticals that lack generic competition, will more than likely continue. This trend, coupled with the fact that $70 \%$ of all prescriptions are covered partially or fully by a third-party payor, ${ }^{1}$ has resulted in increased scrutiny of pharmaceutical dispensing and reimbursement processes.

The audit process is one means of reviewing pharmacy programs; it ensures that procedures and reimbursement mechanisms are consistent with contractual and regulatory requirements. This article presents an overview of the audit process, programmatic issues most likely to be audited, data frequently collected, and guidelines that managers and staff should follow during an audit.

\section{TYPES OF AUDITS}

During an Internal Revenue Service (IRS) audit, the IRS reviews tax returns to verify that a tax obligation was computed according to the tax code. In many respects, a pharmacy audit is similar. The pharmacy program is reviewed to ensure that it is operating according to established guidelines. Pharmacy programs are most likely to be the subject of a financial, compliance, or operational audit.

A financial audit reviews the accuracy of a company's financial statements.
Using standardized accounting techniques, a financial auditor seeks to evaluate a company's fiscal solvency, including the accuracy of its statements of assets and liabilities. Many pharmaceutical companies are publicly traded and have a fiduciary responsibility to their stockholders that must be met through routine financial audits.

A compliance audit seeks to assess a company's level of compliance with operating procedures as stipulated by regulatory or contractual arrangements. For example, every pharmacy that is a contract provider of prescription services is subject to a clause in its provider agreement that allows an audit of the pharmacy's records, including hard-copy prescriptions, signature logs, computerized records of refills, and invoice records. Pharmacies also are subject to any num ber of audits conducted by state or federal licensing agencies.

An operational audit, also referred to as a performance or management audit, evaluates the effectiveness of a business' operating activities in relation to specific objectives. For example, a Pharmacy Benefits Manager (PBM) acts as a thirdparty administrator to various plans. These plans customarily require the PBM to maintain member eligibility and to accurately adjudicate members' benefits under the plan. In addition, the PBM may supply rebates and administer a formulary for the payor, or share discounts with the payor. These relationships are very complex and require 


\section{Table 1. Audit Topics}

$\Delta$ Purchasing and dispensing of controlled substances;

$\Delta$ Accuracy of claims including quantity, dispensing date, dispensing intervals, and prescriber information;

$\Delta$ Product selection criteria for generic versus brand utilization;

$\Delta$ Assuring that special inventory controls exist for government mandated discount programs;

$\Delta$ Proper administration of a benefit plan;

A Assuring that rebates and risk-sharing provisions in a benefit plan are working properly;

$\Delta$ Compliance with contractual requirements for Point of Dispensing programs;

$\Delta$ Accuracy of invoice preparation;

$\Delta$ Compliance with formulary requirements; and

A Suspicion of fraud and abuse.

Table 2. Data Reviewed by Auditors

A Hard-copy prescriptions;

A Computerized dispensing records;

A Physician records to support prescription records;

A Patient signature logs;

A Purchase records and invoices;

A Policies and procedures;

Financial records:

Communications logs;

Provider payment records;

Contracts;

Quality control plans;

A Clients and membership eligibility records and contracts; and

- Computer flowcharts and programs. sophisticated information systems and technology. Given this complexity and the dollars associated with prescription plans, the plan's sponsor will want to audit its PBM vendor for overall efficiency in administering the agreed-upon plan.

\section{THE AUDIT AS A QUALITY CONTROL MECHANISM}

A pharmacy audit is conducted on behalf of a client who usually is external to the organization. Entities that typically request pharmacy audits include state and federal programs such as Medicaid, state licensing boards, drug enforcement agencies, the Internal Revenue Service, and companies that contract with phar macies such as health maintenance organizations and PBMs.

The auditor who conducts the review may be either internal or external to the program. When objectivity is an issue, the auditor typically is external to the program being audited and reports the findings to the client who requested the audit.

Rather than view the audit as an obtrusive and potentially threatening review, pharmacies should see the audit as a quality-control mechanism. Audit findings and corrective actions that result assure all involved parties that a program is operating according to established standards of practice.

Consequently, audits protect companies from potential criticism of its operations. Audit findings can be used to defend legal claims that a company did not abide by the terms of its contracts. And should an audit uncover a lack of clarity in a company's contracting or operating procedures, these findings can be used to improve the organization's performance and minimize its exposure to future business risk. For example, an audit may reveal that a business lacks adequate internal controls for billing, which could lead to unscrupulous employees engaging in fraud and abuse.

It is precisely because of the benefits associated with audits that many companies maintain internal auditing programs. As a business expands, the audit becomes a necessary quality-control mechanism. In fact, some executives interpret a company's first audit as a significant milestone in the company's maturation process.

\section{THE AUDIT PROCESS}

Each audit has different objectives that are applied to individual programs with specific operating procedures. However, despite each audit's uniqueness, all audits generally consist of four major activities.

First, there is the engagement process, in which an auditor is engaged by the client who is seeking to establish compliance, prove financial statement veracity, or measure operational compliance. The purpose of the audit is clearly specified along with the contractual terms between the auditor and the client. The client, not the pharmacy program, has sole right to the audit report and bears the financial obligations for funding the audit. Pharmacy issues most frequently audited are highlighted in Table 1.

Second, there is the audit plan, in which the auditor develops a methodology to conduct the audit. The methodology must specify objective measures and documentation that will be used to judge compliance. The auditor will develop various "tests" to judge compliance, which may include on-site observations of staff working. In the case of record reviews, such as verifying prescription claims, the auditor must design appropriate sampling techniques that generate valid findings from sample sizes, usually ranging from 50 to thousands of records. If the program utilizes computer processing, the auditor may employ measures to test the accuracy of the computer programs employed. An essential audit principle is that another auditor employing the same test measures should arrive at the same findings.

Third is the field work, which consists of the site visit and application of the methodology. The site visit consists of record reviews and interactions with staff through which the auditor applies the 
Continued from page 94

various tests of compliance. During the site visit, the auditor has the right to access all necessary records and documents (See Table 2). This includes information that is considered confidential (e.g., patient information) or proprietary (e.g., reimbursement terms of a competitively solicited contract). Auditors usually will explain the relevance of such information to their work. Should a company deny an auditor's information request, legal opinion may be sought on the matter. This, however, rarely occurs during the audit process. Confidential information generally is reviewed on site, and documents are rarely removed to a remote location. Also, auditors are responsible for maintaining the confidentially of information and are accountable for breaches of this standard.

The fourth activity is the generation of findings and the report, which is a detailed presentation of the methodology and findings of the audit. It frequently includes recommendations for the pharmacy program. Auditing standards require that the auditor report all findings relating to the internal control of the audited program to the client. On occasion, the company that was audited may receive the same information for comment and review. Table 3 lists findings that require reporting under standard auditing procedures.

\section{POST-AUDIT ACTIVITIES}

Following the review of the audit report with the client, the findings of the audit sometimes are shared with the program that was audited. If the audit was conducted by a state or federal agency, regulations generally provide for an appeal process should the program disagree with the findings. For example, a program may be cited as lacking proper procedures for dispensing controlled substances, when in fact the staff simply failed to provide the policy to the auditor. Findings of inadequate control, however, generally are based upon other factors in addition to the absence of written policies and procedures. Most govern- ment audits require a corrective action plan for negative findings, and a program may be required to submit formal documentation that corrections have occurred. Alternatively, another audit may be conducted at a later date.

When findings reveal errors in billing invoices and reimbursements, the client and the program make corrections consistent with the terms of existing contracts. If contracts are lacking, and the parties cannot come to agreement on financial recovery, the courts or an independent arbitrator may be utilized. Audit findings rarely end up before a judge. Seasoned executives generally accept audit findings for what they are-namely, an opportunity for a business to correct operational procedures that may be a bit askew to acceptable practice.

\section{PREPARATION FOR AN AUDIT}

Other than unannounced audits conducted by certain state and federal agencies, most companies are given two to three weeks' notice that their operations will be audited. Once an audit is scheduled, the manager should engage in several proactive steps in preparation for the audit. First and foremost, the manager should understand the purpose of the audit. Is it a financial or compliance audit? Will it entail the entire operation or just a subcomponent? If the purpose is not clear, management should seek clarification.

Once the focus of the audit is understood, try to anticipate the materials that the auditor will review and begin to assemble them. Also, if known problems exist, be prepared to discuss with the auditor planned corrective actions and their target dates. The more clearly the auditor understands these situations, the less likely misunderstandings will occur.

Managers also should inform their staff that the program is being audited and brief the staff on "audit etiquette." Managers must emphasize the need to cooperate with the auditor, and they must inform staff that auditors must have access to all materials requested.
Table 3. Findings That Require Reporting

A Inadequate supervisory control;

A Absence of appropriate separation of duties by workers;

A Absence of appropriate reviews and approvals of financial transactions;

A Inadequate provisions for safeguarding assets;

A Failure to correct known deficiencies;

- Evidence of undisclosed party transactions;

A Evidence of misrepresentations to auditor;

A Evidence of manipulation, falsification, or alteration of records;

A Willful wrongdoing by employees or management; and

A Failure to adhere to regulatory requirements.

When staff members act in an evasive manner, this only arouses the auditor's suspicion. Lack of cooperation will be mentioned in the audit report. Employees should extend the same professional courtesy to auditors that they extend to clients. Every auditor is sensitive to the professionalism of the workplace, which sets the overall context in which operations are judged.

\section{CONCLUSION}

While a letter notifying a manager of a pending audit may not be the most welcomed news, an audit should be viewed as a valuable management tool. It is an essential business process that results in recommendations for improvement. And from a "bottom line" perspective, organizational improvement reflects well on staff, the program, and the profession

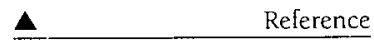

1. IMS Health press release, March 31, 1998. 